\title{
Direct impacts of alternative energy scenarios on water demand in the Middle East and North Africa
}

\author{
Kerstin Damerau • Oscar P. R. van Vliet • \\ Anthony G. Patt
}

Received: 13 April 2013 / Accepted: 29 January 2015 / Published online: 10 February 2015

(C) Springer Science+Business Media Dordrecht 2015

\begin{abstract}
The Middle East and North Africa (MENA) region stands out globally both for the immensity of its energy resources, and the paucity of its freshwater resources. Most energy extraction and conversion technologies have associated freshwater demand, and in the MENA region these account for $2 \%$ of the available sustainable supply. We examine how this demand could change over the 21 st century, assuming growth in population and economic output, and considering three alternative pathways for energy efficiency, carbon intensity, and energy exports from the region. We find that in the pathway marked by improved efficiency, a transition to renewable energy sources, and declining energy exports, water consumption for energy is twice as high as today's values by the end of the century. By contrast, in the pathway marked by continued commitment to fossil resource extraction, use, and export, water demand for energy might rise by a factor of five. If the region were to maintain high levels of energy exports, but would substitute the export of fossil fuels by an equivalent amount of electricity derived from sunlight, a freshwater volume comparable to the household needs of up to 195 million people could be saved.
\end{abstract}

\section{Introduction}

Growing population and economic development have led to a steep rise in energy demand over the last 150 years (Smil 2010, BP 2013). Associated with this trend has been an increasing demand for water resources, as water is required for the extraction, processing and conversion of fossil and renewable energy sources. Technology choices can have a significant impact on the energy sector's water demand, sometimes leading to local and regional water availability being a limiting factor for energy generation (Feeley et al. 2007, Sovacool and Sovacool 2009). When presenting data on this resource interconnection, recent

Electronic supplementary material The online version of this article (doi:10.1007/s10584-015-1345-y) contains supplementary material, which is available to authorized users.

K. Damerau $(\bowtie) \cdot$ O. P. R. van Vliet $\cdot$ A. G. Patt

Department of Environmental Systems Science, Swiss Federal Institute of Technology Zurich (ETH), Universitätstrasse 22, CHN J73.2, 8092 Zurich, Switzerland

e-mail: kerstin.damerau@usys.ethz.ch

A. G. Patt

International Institute for Applied Systems Analysis (IIASA), Schlossplatz 1, 2361 Laxenburg, Austria 
scientific literature focuses mainly on the US (Mielke et al. 2010, Macknick et al. 2012, MacMahon and Price 2011, US DOE 2006), but one finds discussion on this topic also in other parts of the world (FAO 2008, NRAA NN) as well as on a global level (SEI 2011, Kyle et al. 2013, Vassolo and Döll 2005). An ongoing increase in energy demand, declining overall water availability and climate change might further increase water requirements for energy in certain world regions (Sowers et al. 2011, CEDARE 2006, Haddadin 2001), and hence aggravate resource competition with other sectors such as agriculture.

A region that stands out with regard to both energy and water is the Middle East and North Africa (MENA). While having the world's largest reservoirs of fossil energy along with enormous renewable energy resources, MENA is also the region that shows highest water scarcity. Climate policy choices, and the energy technologies they favor, may have a large effect on MENA's fossil energy exports, electricity system and fuel production. Following an increasing energy demand, within the region and globally, the deployment of new fossil and renewable energy technologies might lead to positive or negative feedbacks concerning the water dependency of the energy sector and hence potentially important trade-offs with other water users. In this paper we examine the effect of changing energy technology mixes, a crucial prerequisite to meet global climate and regional development goals, on MENA's water demand. By using the Representative Concentration Pathways (RCPs) (van Vuuren et al. 2011) as a framework, we develop three energy scenarios for the MENA region as a whole, in order to answer the question of whether a transition from fossil fuels to renewable energy sources, both for domestic energy consumption and for energy exports, can also have a beneficial effect on the region's sustainability with respect to water.

\section{Background}

\subsection{Water in the energy system}

Water consumption can be defined as the water volume that gets evaporated, and/ or polluted per unit of time. The terms water demand and water requirements are used synonymously with the term water consumption in this study. There is a range of water qualities that can serve for extraction and conversion of resources in the energy system. Today mostly fresh water is used, water showing a salinity of less than $500 \mathrm{ppm}$. Brackish $(500-30,000 \mathrm{ppm})$ or saline water, such as seawater, with a salinity of 30,000 to $50,000 \mathrm{ppm}$ can also be utilized for many energy technologies, though more intense treatment might be necessary compared to fresh water (Griffiths and Woynillowicz 2003). Water withdrawals, the water amount that is removed from a source, are larger than the actual water consumption, as part of the withdrawn water is returned to the source, often at higher temperatures. For this paper, we chose to focus only on water consumption, as to date data availability and quality for water withdrawal in the extraction and fuel production parts of the energy sector remain insufficient.

Water is required to extract fossil energy from its on- and off-shore reservoirs. Regarding oil extraction, water is primarily used to maintain the underground pressure that forces the oil to the surface. Only small amounts are needed for maintenance, operation and transport. Over time water needs increase in conventional oil reservoirs as they shift from primary to secondary and finally tertiary (enhanced oil recovery [EOR], mainly steam and $\mathrm{CO}_{2}$ injection) extraction. Average water needs for shale oil, oil sand and heavy oil reservoirs are considerably lower than for enhanced oil recovery from conventional oil fields, but often use similar extraction techniques. Coal mining, washing and transport shows lower water consumption factors than conventional oil, while conventional and 
unconventional gas (in MENA mainly shale gas and gas hydrates (Rogner 1997)) extraction requires the least water amounts.

The part of the energy system that has received most attention so far with regard to water use is the electricity sector. Here, water is mainly required for the cooling systems of thermal power plants. Main driving factors for differentiating water demands of power plants appear to be operational as well as thermodynamic efficiency, to a lesser degree ambient temperature, fuel type, water source and age of the cooling system (Yang and Dzieglielewski 2007). Oncethrough and closed-loop are the most common but also most water-intensive cooling systems today, with once-through systems showing highest water withdrawal rates and closed-loop systems highest water consumption. In more arid regions the shares of dry cooling systems, seawater cooling or a mix of wet and dry, hybrid cooling systems are higher. Regarding fuel processing, fossils and most renewables such as bio-ethanol require water both for extracting the fuel from the energy source and for cooling. When emission capturing (such as $\mathrm{CO}_{2}$ or $\mathrm{SO}_{2}$ ) is not already part of the extraction and processing of fuels and electricity generation, additional water demand occurs - especially for Carbon Capture and Storage (CCS) technologies that rely solely on wet cooling systems at this time, which in turn require considerable amounts of water (Zhai et al. 2011).

\subsection{Water use analyses}

Analyses of the water requirements, both withdrawal and consumption, of energy extraction and conversion so far have mostly focused on the United States (US) (Harte and El-Gasseir 1978, Gleick 1994, DOE 2006, Mielke et al. 2010, Macknick et al. 2011, 2012), where locally water shortages can limit potential energy production. Information on fossil fuel extraction are limited and mostly stem from case studies in the US or Canada (Argonne 2008, Griffiths and Woynillowicz 2003, NRTEE 2010, CAPP 2012). Data on fuel production can be found in various smaller studies like Van Vliet et al. (2009), Spath and Mann (2001) or Naterer et al. (2010). Regarding electricity generation, there is a series of reports analyzing and comparing different power plant technologies. The most complete to date is Macknick et al. (2012), which presents the comprehensive ranges of water demand from various US reports and studies over the last decades, and constitutes also the main basis for our analysis of MENA's electricity sector. As a result of the high amount of surveyed literature in Macknick et al. (2012), data ranges are relatively wide. Comparing these comprehensive results to more geographically confined studies from Australia (Smart and Aspinall 2009), Europe (Carillo and Frei 2009) or North Africa (Damerau et al. 2011), data usually fall within the ranges presented for the US. The share of different types of cooling systems has a fundamental impact on the overall water demand of the electricity sector. As reported in Davies et al. (2013), data on a global level are hard to obtain. We adopted cooling system shares from this study for the MENA region, where currently seawater cooling stands out as the preferred cooling technology. The water demand for hydropower appears to be exceptionally high as it refers to the evaporative loss of water from reservoirs that usually serve multiple purposes. Therefore we mostly disclose this water demand separately within our overall calculations, especially as hydropower capacities increase in our energy scenarios. A stage of energy production where additional water demand occurs is plant construction. Current reports and studies used as basis for our analysis do not include full life-cycle water usage, focusing only on operational and maintenance water demand. A full life-cycle analysis for the US electricity sector can be found in Fthenakis and Kim (2010). A comprehensive overview of the current ranges and average water use requirements for different energy technologies can be found in Table S1 in the Supplementary Material (SM). 
So far, relatively little analysis has focused on the Middle East and North Africa region or its constituent countries, and most regional studies on water demand for energy focus solely on the electricity sector. Regional findings are presented in Davies et al. (2013) as part of a global study. Basis for their analysis of the Middle East is a study by Vassolo and Döll (2005), also a global analysis of water demands in the electricity sector, where assumptions on water consumption of thermal power plants appear to be somewhat lower when compared to our analysis. A more comprehensive study on the whole energy sector in MENA can be found Siddiqi and Anadon (2011). Making use of similar data sources to ours, quantitative results are presented only for parts of the energy sector, and hence only allow a limited comparison with our study.

Despite being of minor importance with regard to the total water use in the entire region today (Siddiqi and Anadon 2011; FAO 2014), expected declining water resources and a rising energy demand might lead to a considerable increase in the water demand and therefore increased competition with other water users. Depending on energy sources and technologies chosen, we investigate the current and future reliance of the whole energy sector on water in this particularly water-scarce region.

\section{Methods}

\subsection{Framework for regional energy scenarios}

The frame for our outlook in MENA's energy future until 2100 is set by the regional emission trajectories embedded into a set of global pathways on radiative forcing. These Representative Concentration Pathways were developed for a new scenario approach to anthropogenic climate change for the IPCC Fifth Assessment Report (IPCC 2013) and give a wide range of potential greenhouse gas (GHG) emission developments from 2.6 to $8.5 \mathrm{~W} / \mathrm{m}^{2}$ of global radiative forcing. Fitting our scenarios into this framework facilitates potential comparison with other scenarios in the scientific literature. We take the lower and upper boundary to explore how MENA's energy sector could develop in face of strong population growth (UN DESA 2009, UN 2010) and therefore rising energy demand, both for electricity and fuels, while possibly opposed by climate change mitigation measures (Riahi et al. 2007, IEA 2009, Nakicenovic and Swart 2000). In the lower boundary pathway GHG concentrations peak globally at about 490 ppm $\mathrm{CO}_{2}$-equivalent before 2100 and decline thereafter, while the upper boundary pathway shows concentrations rising beyond $1,370 \mathrm{ppm} \mathrm{CO}_{2}$-equivalent. We selected these two pathways to present the most optimistic (RCP2.6) as well as most pessimistic (RCP8.5) outlook regarding the global $\mathrm{CO}_{2}$ concentration until 2100. As the other two pathways, 6.0 and 4.5 , lead to a stabilization of $\mathrm{CO}_{2}$ concentrations between the IPCC's 2.6 and 8.5 pathways, they would likely show a stronger mix of both fossil and renewable energy over the next decades. Because our scenarios mainly favor either one or the other, we are able to see stronger effects on the overall water demand when comparing different technologies as a part of energy scenarios.

\subsection{Calculating current water demand for energy}

We derived detailed data on MENA's current energy sector from the online database of the International Energy Agency (IEA) referring to the year 2008 (IEA 2008). The IEA database offers, inter alia, data on fossil resource extraction and domestic processing and (sectoral) consumption as well on trade and stock changes of fossil and renewable energy sources. 
Multiplying these data with our collected water consumption data, if possible regionally specific, allowed us to calculate the current water demand of the entire sector. For estimating the shares of extraction technologies for conventional and unconventional oil extraction, we used shifting rates from the US and applied them to MENA, where commercial oil recovery began on average about two decades later. We assumed that unconventional resources like shale oil, oil sand and heavy oil play only a minor role, with a share of $10 \%$ within all unconventional recovery methods, leaving $90 \%$ to EOR methods with similar shares in technologies like found in the US today (Mielke et al. 2010). Cooling system shares for electricity generation in the region were adopted from estimates in Davies et al. (2013). To be able to relate our results to MENA's total water resources and use, we collected data from the AQUASTAT online database of the Food and Agriculture Organization (FAO 2014), which offers recent data (2003-2007, partially estimated or modeled, published in 2014) on a country level including renewable freshwater resources. Though this database does not include actual data on water consumption in MENA, total water withdrawal can give us an approximation: $96 \%$ of all water is withdrawn for agricultural purposes, where due to high evaporation losses water consumption is assumed to follow withdrawal rates very closely (compare Water Footprint database (Hoekstra and Mekonnen 2012)).

\subsection{Scenario development}

We used the MESSAGE integrated assessment model to draw the two regional energy futures that present a detailed potential mix of energy technologies. MESSAGE provides a mid- to long-term framework for representing an energy system on a regional or global scale (consequently, we looked at the MENA region as one entity), and included interdependencies from resource extraction and conversion to sectoral consumption and international trade (Messner and Strubegger 1995, RCP Database 2009) The two base scenarios all satisfy the GHG emissions constraints associated with RCP 2.6 and 8.5, as well as assumptions about regional resource potentials and energy technology developments available to meet the regional energy demand of growing populations and economies (UN DESA 2009, Riahi et al. 2007). Starting our scenarios in 2010, and extracting results in 10-year steps until the end of this century, we multiplied MESSAGE's technology-specific energy supply data for each scenario with the average water consumption factors presented in Table S1 (see SM). In neither scenario, RCP2.6 and RCP8.5, do electricity exports play a role. This is an artifact of the scenario modeling environment, which does not explicitly take weather-driven variability from renewables into account, but rather deals with it indirectly by placing constraints on the fraction of electricity from particular intermittent sources. There are reasons to believe mixing renewably generated power from widely dispersed locations and transmitting them via high-voltage direct current (HVDC) lines, as well as relying on concentrating solar power with the possibility of thermal storage (in contrast to photovoltaics, and therefore the preferred solar energy technology by the energy model), could help to alleviate load management issues that grid operators face, and would make solar power from MENA an attractive import commodity in neighboring regions (Battaglini et al. 2009, Pfenninger et al. 2014). As a result we developed a third scenario, representing a hybrid of the other two and of particular relevance to the MENA region, which relies on energy exports for its economic base and might continue to do so in future. The hybrid scenario maintains total domestic energy use and greenhouse gas emissions, as well as fossil fuel (oil and gas) exports, at the level of the RCP 2.6 consistent scenario, while maintaining total net energy exports at the level of the RCP 8.5 consistent scenario. In this hybrid scenario, MENA intensifies the use of its solar potential and closes the gap between total fossil fuel exports in RCP2.6 and RCP8.5 through exports of 
electricity generated by concentrating solar power (CSP), resulting in a mix of fossil and renewable energy exports.

As more and more conventional oil reservoirs get depleted and unconventional resources have to be explored in order to meet a growing energy demand, extraction technologies shift to more water-intensive technologies. Note that the MESSAGE model lists fossil fuels from tertiary extraction techniques (EOR) as unconventional resources. The shares of secondary and tertiary oil recovery are expected to increase over time. To be able to incorporate these shifts, we assumed the same average shift rates observed in the US, resulting in levels of $30 \%$ primary, $60 \%$ secondary and $10 \%$ EOR today (Mielke et al. 2010) and assuming a share of $30 \%$ saline water consumption. Extrapolating this trend, we arrive at a share of $60 \%$ secondary and $40 \%$ EOR in MENA in 2100, holding the share of saline water consumption stable at $30 \%$. We also held shares of EOR technologies stable at current US levels, as any changes in future technology trends are hard to predict. As for the other unconventional resources, shale oil, oil sand and heavy oil, that are not part of the fossil fuel mix in MENA today but might be to a small degree in future according to our scenarios, we adopted current resource shares (IEA ETSAP 2010) with the majority being heavy oil, and technology shares for oil sand from Canada (NRTEE 2010). Over time, we then steadily adjusted today's shares to presumably available resource shares, which show quite equally distributed reserves globally, and specifically for oil sands a higher potential for in situ than surface mining (IEA ETSAP 2010, Griffiths and Woynillowicz 2003). Water requirements therefore increase slightly over time, but including an assumed constant share of $20 \%$ for saline water consumption and making an overall contribution of only $10 \%$ to unconventional oil resources, this effect remains minor. Water consumption factors for coal and gas extraction (conventional and unconventional) were held stable; no uranium mining takes place in the MENA region.

Regarding shares of cooling systems in the electricity sector, we do not assume changes for specific technologies. Today the majority of MENA's thermal power plants is seawater cooled and is expected to continue to use these cooling systems in future, as those plants are primarily located along the more densely populated coast lines. In our study main drivers for a changing water demand on a technological level is therefore the deployment of new, renewable capacities, especially CSP where the choice if cooling systems has a large impact of the electricity sector's water demand in future. Depending on their location, seawater cooling like for existing fossil power plants appears to be less efficient with regard to potential power output of CSP plants. Hence, we assume new CSP capacities placed more inland (compare Pfenninger et al. 2014) with an equal share of the two currently most common technologies, parabolic trough and tower, where we find higher solar potentials but seawater cooling is not a viable option. In our scenarios we present results for both wet and dry cooled CSP.

Today, main resources exported from MENA to other world regions are crude oil and gas, while refinery fuels only play a minor role. The amount of assumed future energy exports in MESSAGE depends on global and domestic fossil fuel demand in the energy scenario, regional resource availability and estimated energy cost. Therefore fossil fuel export plays a larger role in RCP8.5 than in RCP2.6. MESSAGE does not include potential electricity trade, but was added in our hybrid scenario as a feasible option in form of solar electricity export to neighboring world regions.

\section{Results}

Applying the average water consumption factors, presented in Table S1, to the mix of plant capacities that are currently represented in MENA's energy sector allowed us to estimate the 
actual water consumption for energy in the region. For 2008 we calculated a total freshwater consumption of 9.4 billion $\mathrm{m}^{3} .7 .1(76 \%)$ of these 9.4 billion $\mathrm{m}^{3}$ are attributed to fossil resource extraction, and another 0.04 billion $\mathrm{m}^{3}$ to the refining of oil products (higher amount than estimated by Siddiqi and Anadon (2011)). Together, fossil fuels require $1.7 \%$ of MENA's available renewable freshwater supply of 425 billion $\mathrm{m}^{3}$ (FAO AQUASTAT 2014). Figure 1 shows these results, disaggregating the fossil fuel water demand according to shares for domestic supply (30\%) and international exports (70\%). Much less fresh water, 2.2 billion $\mathrm{m}^{3}$, is required for electricity generation. $44 \%$ of that constitutes evaporative loss from hydropower plants, half of this from Egypt's Lake Nasser (IEA 2008). Comparing to Davies et al. (2013), we calculate a water consumption of $0.9 \mathrm{bn} \mathrm{m}^{3}, 0.15 \mathrm{bn} \mathrm{m}^{3}$ more, for the electricity sector in the Middle East (both excluding hydropower) - this difference can be explained by larger water consumption factors used in our study. There are no total comparable water consumption data available from FAO AQUASTAT for MENA. However, according to this database, total current water withdrawal reaches 300 billion $\mathrm{m}^{3} /$ year, of which $96 \%$ are used in the agricultural sector, leaving to assume that total water consumption reaches only slightly lower levels.

As a next step, we analyzed MENA's future water consumption for energy. The three scenarios, RCP2.6, hybrid, and RCP8.5, describe the same levels of population and economic growth in MENA (MESSAGE assumes the economy continues to grow steadily around current levels), but differ according to the energy intensity of the economy and the carbon intensity of energy use. Regarding the former, primary energy demand in the MENA region

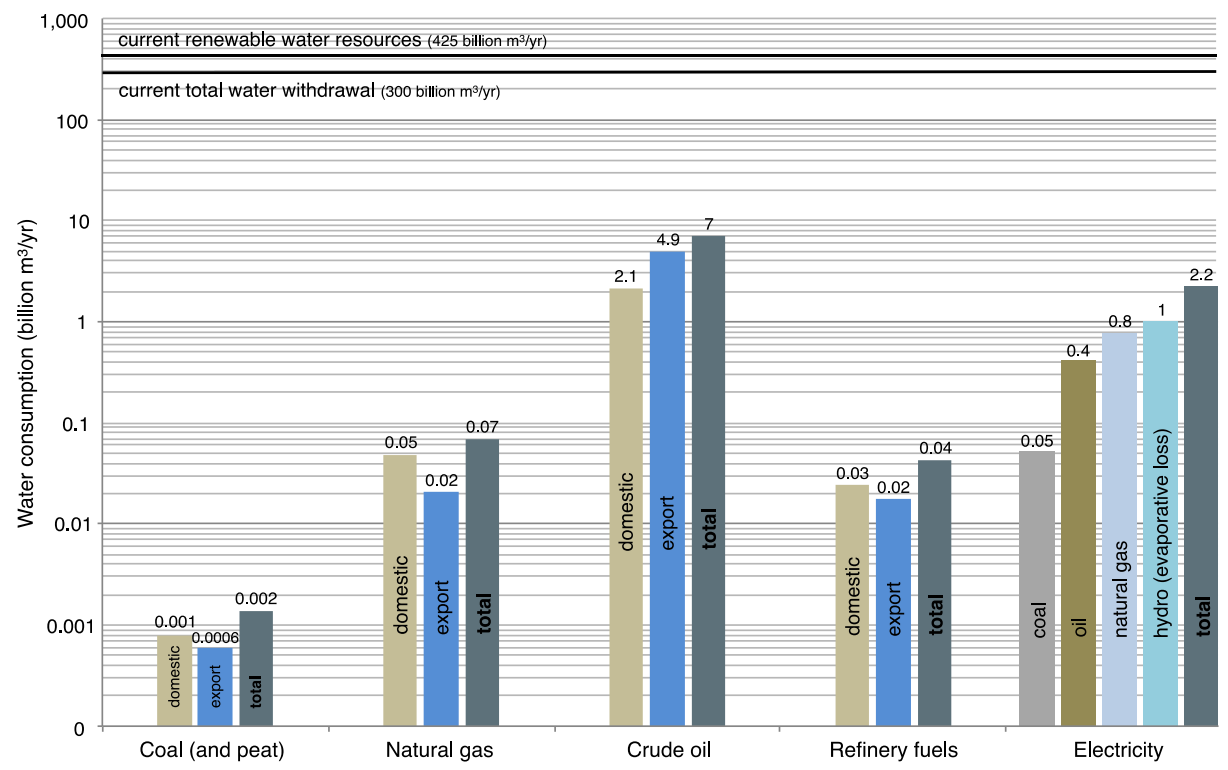

Fig. 1 Current water consumption of MENA's energy sector. The countries included are Algeria, Bahrain, Egypt, Iran, Iraq, Israel, Jordan, Kuwait, Lebanon, Libya, Morocco, Oman, Palestine, Qatar, Saudi Arabia, South Sudan, Sudan, Syria, United Arab Emirates and Yemen. Data are presented on a logarithmic scale. For each fossil resource, the bars indicate the water use requirements associated with extraction to supply energy use within the MENA region, and associated with extraction bound for exports from the region. Separate bars for electricity identify water needs at the point of energy conversion, in the case of fossil fuels primary for the cooling of thermal power stations. Renewable water resources refer to actual total renewable water resources (FAO AQUASTAT, 2014) 
rises from $33 \mathrm{EJ} /$ year to $46 \mathrm{EJ} / y e a r$ in the $\mathrm{RCP} 2.6$, and $200 \mathrm{EJ} / \mathrm{year}$ in the RCP8.5 scenario. Regarding the latter, MENA's fossil fuel extraction in the RCP2.6 scenario peaks in 2030 at $120 \mathrm{EJ} /$ year and then steeply declines to $33 \mathrm{EJ} /$ year by 2100 . The emissions these fossil fuels generate are compensated through the use of carbon capture and storage (CCS). Conventional oil and gas continue to be the major fossil resources extracted. Unconventional oil extraction is not necessary to meet the demand, and unconventional gas extraction is phased out by 2030 .

In the RCP8.5 scenario, by contrast, there is strong increase in fossil resource extraction, to a maximum of $225 \mathrm{EJ} /$ year in 2100, making unconventional oil the major energy resource from 2040 onward. Perhaps surprisingly, crude oil and gas exports decline not only in the RCP2.6 but also in the RCP8.5 scenario, although the decline is steeper in the former, $88 \%$ compared to $55 \%$. However, the export of oil products such as fuel oil increases in both scenarios. Overall export of fossil fuels declines by $68 \%$ in the RCP2.6 scenarios but increases by $16 \%$ in RCP 8.5 until the end of the century. The driving factor for the decrease in exports in the RCP2.6 scenario is the global shift away from fossil fuel combustion, whereas in the RCP8.5 scenario no such export limitations occur and make fuel instead of crude resource exports an economically more attractive option in future. Figure 2 presents an overview of these regional energy scenarios, conforming in their GHG emissions to the lower and upper global RCPs. Table 1 gives additional information on total energy and renewable energy demand changes between the start year 2010 and 2100 for all three scenarios.

Applying the technology specific water consumption factors to these three energy scenarios, we draw a potential picture of water consumption in the energy sector over the coming decades. Figure 3 displays aggregate water consumption by the MENA energy sector associated with each scenario; additional results, further decomposing that water demand by technology, appear in the SM. For the RCP2.6 scenario, water consumption peaks in the first half of the century at almost three times the current level, and then declines thereafter, as fossil fuel extraction for both domestic use and exports falls off. By 2100, annual water demand is still about twice as high as today, at 18 billion $\mathrm{m}^{3}$, but the relative shares for fossil fuel extraction and electricity generation have roughly reversed. In the RCP8.5 scenario, by contrast, water consumption peaks higher and later. In 2080, total water demand lies at 52 billion $\mathrm{m}^{3}$, about six times today's level, and then declines to 47 billion $\mathrm{m}^{3}$ by the end of the century. Shrinking population numbers are the main driver for this decrease. The hybrid scenario tracks the RCP2.6 scenario in all respects, except for the additional water demand
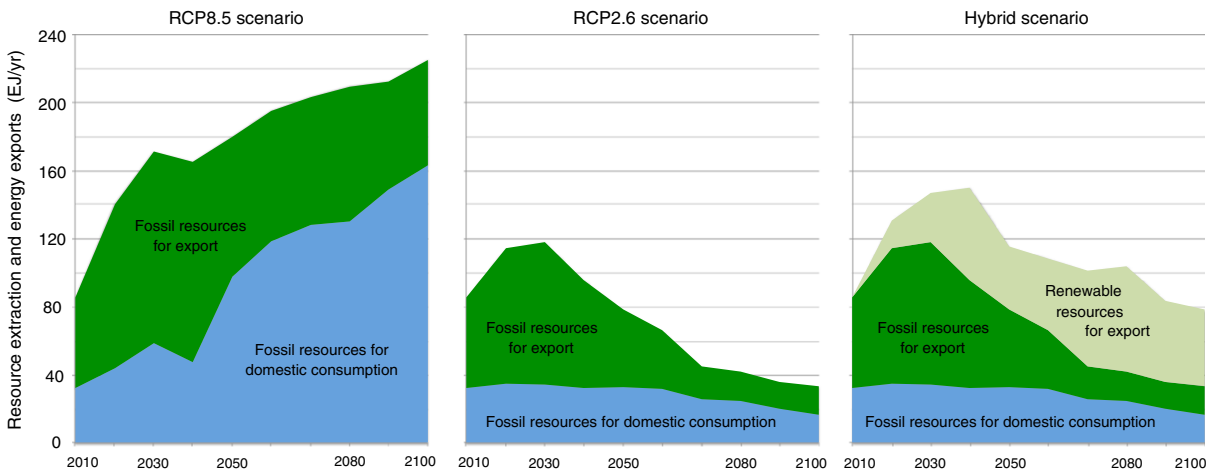

Fig. 2 Total fossil resource extraction and energy exports in MENA through 2100. Comparing three regional energy scenarios, the blue area in each graph represents extraction for domestic consumption, while green areas represent energy resources destined for export markets. The light green shaded area in the hybrid scenario represents the amount of solar energy that is required to increase total energy export from RCP2.6 to RCP 8.5 levels 
Table 1 Total energy demand (extracted fossil resources plus produced non-fossil fuels and electricity) and export in all scenarios as depicted in Fig. 2. The domestic electricity demand in RCP2.6 and the hybrid scenario is met to $95 \%$ by renewables until 2100 , in RCP8.5 $65 \%$ renewables finally meet the regional electricity demand

\begin{tabular}{llccc}
\hline Scenario & 2010 & & 2100 \\
& (Starting year) & RCP2.6 & Hybrid & RCP8.5 \\
\hline Total energy demand [EJ] & 86 & 78 & 122 & 276 \\
Energy export [EJ] & 53 & 18 & 62 & 62 \\
Total share renewable energy [\%] & 0.6 & 57.2 & 72.7 & 18.3 \\
Total share renewable energy export [\%] & 0.0 & 0.0 & 71.0 & 0.0 \\
\hline
\end{tabular}

associated with renewable electricity generation for exports from CSP. Under baseline assumptions concerning generation technologies, the water demand for renewables-based exports is consistently lower than that for crude and refined oil and gas exports. In 2080, when the difference has the greatest absolute magnitude, fossil fuel exports in the RCP8.5 scenario account for 14.1 billion $\mathrm{m}^{3}$ more water consumption than the corresponding electricity exports in the hybrid scenario.

The largest factor driving this growth is the rising water demand for unconventional fossil resource extraction (especially EOR), followed by the generation of electricity; in both cases we have made critical assumptions based on the best available evidence: In the case of unconventional fossil resource extraction, the critical assumption is that primarily fresh water will be used to enhance recovery; the use of saline water above our assumed $30 \%$, could

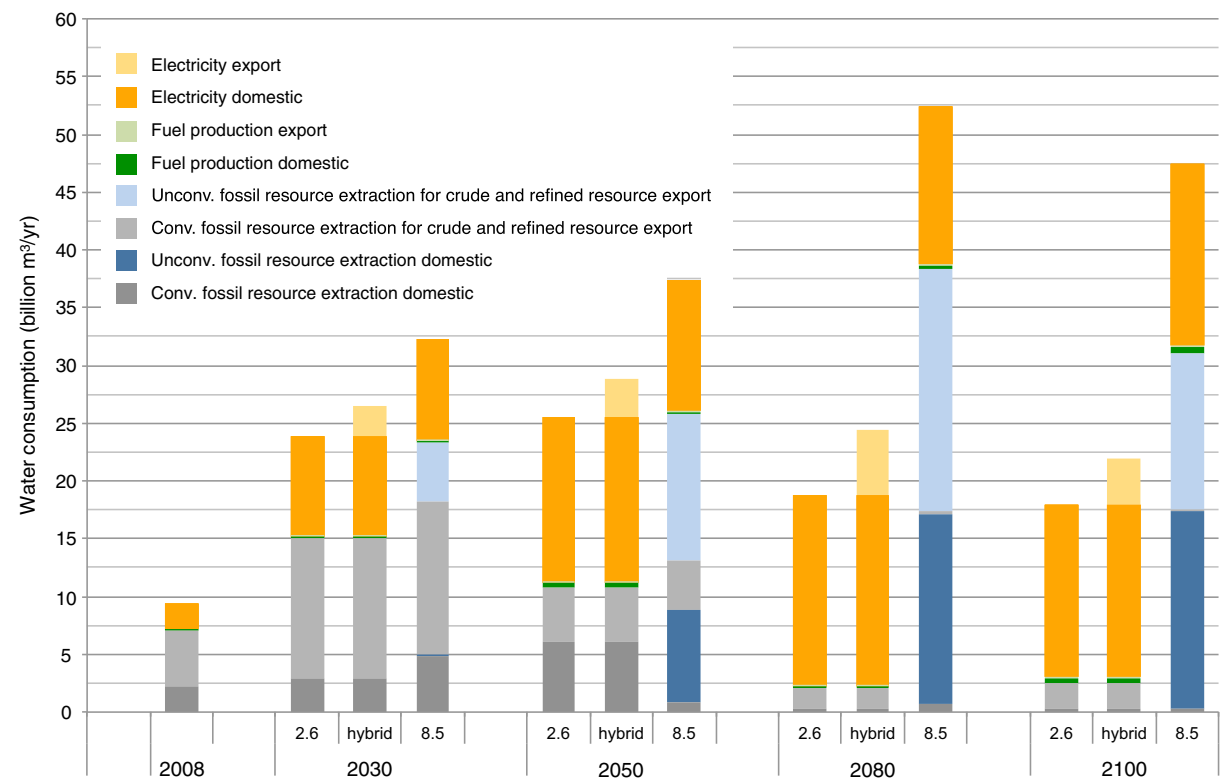

Fig. 3 Overall water consumption for MENA's energy supply through 2100. Bars present each stage of the energy sector and their respective export shares in lighter shades, while conventional and unconventional fossil resources are highlighted separately. Values for the RCP2.6 and hybrid scenario are identical except for water demand for solar electricity exports in the latter scenario. In comparison to RCP8.5, water savings achieved in the hybrid scenario amount to a maximum of 14.1 billion $\mathrm{m}^{3}$ in 2080 and decline thereafter to 7.6 billion $\mathrm{m}^{3}$ in 2100 . Detailed analyses for all three scenarios can be found in the SM 
reduce this water demand at some sites in MENA. In the case of electricity production, our scenarios assume that all new CSP plants are constructed away from the coast and utilize dry cooling, a technology currently available and prevalent in dry climates, but carrying a slight cost penalty compared to wet cooling (Damerau et al. 2011). Were wet cooling to be installed, total water demand for electricity generation would be substantially higher by 2100 : by 26 billion $\mathrm{m}^{3}$ in the RCP2.6 scenario, 33 billion $\mathrm{m}^{3}$ in the RCP8.5 scenario, and 56 billion $\mathrm{m}^{3}$ in the hybrid scenario. Indeed, water consumption for energy exports would be 2.6 times higher in the hybrid scenario than in the RCP8.5 scenario, were wet-cooled CSP the technology delivering the electricity for export. Additional information can be found in the SM.

\section{Discussion}

Our study provides a new, more detailed approach to analyzing the implications on water resources of different potential energy pathways in the MENA region. Continued development along a fossil-fuel intensive pathway, consistent with the RCP8.5 scenario, would mean that the energy sector would have to find sources for roughly five times the amount of water than it requires today. The share of the region's renewable water resources that the energy sector currently demands, slightly more than $2 \%$, is small, and yet this could easily change. In the RCP8.5 scenario, it rises to $11 \%$ of current renewable water resources, resources that are likely to decline over the next decades. The main driver for this trend is the water demand associated with rising levels of unconventional fossil resource extraction. By contrast, a strong commitment to energy conservation and a transition from fossil fuels to renewable energy sources, consistent with the RCP2.6 scenario, could result in a much smaller change in water demand by the energy sector, despite a rapidly growing population. Indeed, it appears that MENA could sustain high levels of energy exports, with much less demand on freshwater reserves, were those exports to shift from its fossil resources to its solar resources, when assuming that solar thermal power plants use dry instead of wet cooling systems, and hence accepting an only marginal economic disadvantage in order to save water resources (Damerau et al. 2011). If we consider, for example, the maximum net water savings of 14.1 billion $\mathrm{m}^{3} /$ year around 2080 that would result from shifting exports from oil and gas to solar power, this amount is comparable to MENA's current domestic water needs of roughly 195 million people, $30 \%$ of the total population for the MENA region projected for 2050 (Chapagain and Hoekstra 2004, UN DESA 2009).

While they do deliver valuable insight, our results have important limitations, due to many of the assumptions that we were forced to make. First, our scenarios include only slight use of CCS added to conventional electric power plants within the MENA region, though for reaching certain emission goals this technology could play a significant role in the future. If large capacities would be installed in water-stressed regions like MENA, the need for drycooled facilities would emerge, as current CCS technologies entirely rely on wet cooling (Zhai et al. 2011). Second, regarding unconventional oil extraction (primarily EOR in MENA) the share of technologies chosen in future can be an important driver for water demand. Third, our results do not include additional water demand that would be required for crop production if first generation bioenergy would be produced in the region. As MENA's potential for bioenergy is considered very low, this energy source is not part of our scenarios, but it may lead to significantly increased water demands for renewable energy in other world regions. There are also only minor regional fissile resources in the MENA region (BGR 2009) and a shift towards nuclear power plants would therefore largely depend on uranium imports. Fourth, we do not assume any changes in water use efficiency for the fuel and electricity technologies 
themselves, as any assumptions at this point seem highly speculative. Fifth, our scenarios are just three potential paths for MENA's energy sector development until the end of the century, and all of them rely on a single scenario for population and economic growth. Sixth, MENA countries differ substantially from one another, and our results provide only a regional view. Scaling down from the regional level would require the use of much more detailed national data. Our results suggest that this may well be a worthy exercise.

Despite the differences between countries, the MENA region as a whole is characterized by extreme water scarcity, where every drop of consumption faces competition from some other user. With a growing population, there is every reason to believe that this competition will grow even more intense in the future. Given the importance of energy exports for the economies of MENA countries, there is also reason to suspect that the water needs of that sector would be met, even if it meant cutting back on water use elsewhere. Currently the agriculture sector is the dominant freshwater user, and yet the implications of failing to conserve water in the energy sector are nevertheless large. The potential feedbacks, which we do not address in this paper, are also large. If 195 million people - the number we highlighted in the previous paragraph — were to rely on desalinated water for their household needs, this would require 75-355 EJ/year, depending on desalination method chosen (WSTB 2008). Comparing that to the region's current energy demand of roughly $53 \mathrm{EJ} / \mathrm{year}$, it becomes obvious that the future linkages between energy and water are important and complex, and a more integrated approach to water resource management is required when facing future challenges of food and energy security.

Acknowledgments Funding for this work was an internal seed grant for cross-cutting research, the Greenhouse Gas Initiative, from the International Institute for Applied Systems Analysis, Austria, as well as a European Research Council consolidator grant, award number 313553. Any remaining errors of analysis are our own.

\section{References}

Anze M, Alves RMB, Nascimento CAO (2010) Optimization of water use in oil refinery. http://aiche.confex. com/aiche/2010/webprogrampreliminary/Paper201402.html. Accessed Jan 2012

Battaglini A, Lilliestam J, Haas A, Patt A (2009) Development of SuperSmart Grids for a more efficient utilisation of electricity from renewable sources. J Clean Prod 17(10):911-918

British Petrol (BP) (2013) BP statistical review of world energy. June 2013. http://www.bp.com/content/dam/bp/ pdf/statistical-review/statistical_review_of_world_energy_2013.pdf. Accessed Jan 2013

Canada. National Round Table on the Environment and the Economy (NRTEE) (2010) Changing currents. Water sustainability and the future of Canada's natural resource sectors. http://www.blue-economy.ca/sites/default/ files/reports/resource/changing-currents-water-report-eng-1.pdf. Accessed Jun 2012

Canadian Association of Petroleum Producers (CAPP) (2012) Water Us in Canada's oil sands. http://www.capp. ca/getdoc.aspx?Docid=193756. Accessed Jul 2012

Carillo AMR, Frei C (2009) Water: a key resource in energy production. Energ Policy 37:4303-4312

Centre for Environment and Development for the Arab Region and Europe (CEDARE) (2006) Water conflicts and conflict management mechanisms in the Middle East and North Africa Region. http://water.cedare.int/ cedare.int/files15\%5CFile2862.pdf. Accessed Jun 2012

Chapagain AK, Hoekstra AY (2004) Water footprints of nations. Vol. 2: appendices. research report series No. 16. http://www.waterfootprint.org/Reports/Report16Vol2.pdf. Accessed Apr 2012

Damerau K, Williges K, Patt AG, Gauché P (2011) Costs of reducing water use of concentrating solar power to sustainable levels: scenarios for North Africa. Energ Policy 39:4391-4398

RCP Database, version 2.0 .5 (2009) http://www.iiasa.ac.at/web-apps/tnt/RcpDb. Accessed Jun 2012

Davies EGR, Kyle P, Edmonds JA (2013) An integrated assessment of global and regional water demands for electricity generation to 2095. Adv Water Resour 52:296-313

Argonne National Laboratory (US DOE) (2008) Water issues associated with heavy oil production. http://www. perf.org/images/Archive_HeavyOilReport.pdf. Accessed Mar 2013 
Federal Institute for Geosciences and Natural Resources (BGR) (2009) Reserves, Resources and Availability of Energy Resources 2010

Feeley TJ III et al (2007) Water: a critical resource in the thermoelectric power industry. Energy 33:1-11

Food and Agriculture Organization of the United Nations (FAO) (2008) Water for agriculture and energy in Africa. The challenges of climate change. Conference report, Dec 15-17, Sirte Libyan Arab Jamahiriya

Food and Agriculture Organization of the United Nations (FAO). AQUASTAT: FAO's global information system on water and agriculture. http://www.fao.org/nr/water/aquastat/main/index.stmS. Accessed Mar 2014

Fthenakis V, Kim HC (2010) Life-cycle uses of water in U.S. electricity generation. Renew Sustain Energ Rev 14:2039-2048

Gleick PH (1994) Water and energy. Annu Rev Energy Environ 19:267-299

Griffiths M, Woynillowicz D (2003) Oil and troubled waters. Reducing the impact of the oil and gas industry on Alberta's water resources. Pembina Insitute for Appropriate Development

Haddadin MJ (2001) Water scarcity impacts and potential conflicts in the MENA region. Water Int 26(4):460470

Harte J, El-Gasseir M (1978) Energy and water. Science 199:623-634

Hoekstra AY, Mekonnen MM (2012) The water footprint of humanity. Proc Natl Acad Sci 109(9):3232-3237

International Energy Agency (IEA) Energy Technology Systems Analysis Programme (ETSAP) (2010) Unconventional oil and gas production. http://iea-etsap.org/web/HIGHLIGHTS\%20PDF/P02-Uncon\% 20oil\&gas-GS-gct\%201.pdf. Accessed Mar 2014

International Energy Agency (IEA) Statistics by country (2008). http://www.iea.org/stats/index.asp. Accessed Dec 2012

International Energy Agency (IEA) (2009) World energy outlook. http://www.iea.org/textbase/nppdf/free/2009/ weo2009.pdf

IPCC (2013) Climate change 2013: the physical science basis. Contribution of Working Group I to the Fifth Assessment Report of the Intergovernmental Panel on Climate Change [Stocker, T.Fet al. (eds.)]. Cambridge University Press, Cambridge, UK, and New York, NY, USA

Kyle P et al (2013) Influence of climate change mitigation technology on global demands of water for electricity generation. Int J Grennh Gas Control 13:112-123

Levin DB, Pitt L, Love M (2004) Biohydrogen production: prospects and limitations to practical application. Int J Hydrog Energ 29:173-185

Macknick J et al. (2011) A review of operational consumption and withdrawal factors for electricity generating technologies. Technical Report NREL/TP-6A20-50900. http://www.nrel.gov/docs/fy11osti/50900.pdf. Accessed Aug 2014

Macknick J et al (2012) Operational water consumption and withdrawal factors for electricity generating technologies: a review of existing literature. Environ Res Lett 7:045802

MacMahon JE, Price SK (2011) Water and energy internactions. Annu Rev Environ Resour 36:163-191

Messner S, Strubegger M (1995) User's guide for MESSAGE III. International Institute for Applied Systems Analysis, Laxenburg, WP-95-69

Mielke E, Anadon L, Narayanamurti V (2010) Water consumption of energy resource extraction, processing, and conversion. Energy Technology Innovation Policy Research Group, Belfer Center, Harvard Kennedy School. http://belfercenter.ksg.harvard.edu/files/ETIP-DP-2010-15-final-4.pdf. Accessed Sept 2012

Nakicenovic N, Swart R (2000) Special report on emissions scenarios, International Panel on Climate Change. Cambridge University Press, Cambridge

Naterer GF, Jaber O, Dincer I (2010) Environmental impact comparison of steam methane reformation and thermochemical processes of hydrogen production. In: 18th World Hydrogen Energy Conference 2010 WHEC 2010 Parallel Sessions Book 3: Hydrogen Production Technologies - Part 2 Proceedings of the WHEC, Stolten D, Grube T (eds.), May 16-21 2010, Essen

National Renal Administrators Association (NRAA) (NN) Food security, water and energy nexus in India. http:// nraa.gov.in/FoodSecurityWaterAndEnergyNexus.pdf. Accessed Jan 2012

Owen M (2006) Reduction of water use in wet FGD systems. NETL Project DE-FC26-06NT42726

Pfenninger S et al (2014) Potential for concentrating solar power systems to provide baseload and dispatchable power. Nat Clim Change, published online 06/22/2014

Riahi K, Grübler A, Nakicenovic N (2007) Scenarios of long-term socio-economic and environmental development under climate stabilization. Technol Forecast Soc Chang 74(7):887-935

Rogner HH (1997) An assessment of world hydrocarbon resources. Annu Rev Energy Environ 2:217-262

Siddiqi A, Anadon LD (2011) The water-energy nexus in Middle East and North Africa. Energ Policy 39:45294540

Smart A, Aspinall A (2009) Water and the electricity generation industry. Implications of use. Waterlines Report Series No. 18, National Water Commission, Canberra

Smil V (2010) Energy transitions: history, requirements, prospects. Praeger, Santa Barbara, Denver, Oxford 
Sovacool BK, Sovacool KE (2009) Identifying future electricity-water tradeoffs in the United States. Energ Policy 37:2763-2773

Sowers J, Vengosh A, Weinthal E (2011) Climate change, water resources and the politics of adaptation in the Middle East and North Africa. Clim Chang 104:599-627

Spath PL, Mann MK (2001) Life cycle assessment of hydrogen production via natural gas steam reforming. NREL Report TP-570-27637. http://www.nrel.gov/docs/fy01osti/27637.pdf. Accessed Nov 2012

Stockholm Environment Institute (SEI) (2011). Understanding the Nexus. Background paper for the Bonn2011 nexus Conference. http://www.water-energy-food.org/documents/understanding_the_nexus.pdf. Accessed Nov 2012

UN DESA (2009) World population prospects: the 2008 Revision database. Working Paper No. ESA/P/WP.210, United Nations Department of Economic and Social Affairs

UN (2010) Population Division, World Population Prospects: The 2010 Revision. http://esa.un.org. Accessed Feb 2013

U.S. Department of Energy (DOE) (2006) Energy Demands on Water Resources. Report to Congress, Washington, DC. /http://www.sandia.gov/energy-water/docs/121-RptToCongress-EWwEIAcommentsFINAL.pdf. Accessed Aug 2012

U.S. Department of Energy (DOE) (2009) Concentrating solar power commercial application study: reducing water consumption of concentrating solar power electricity generation. Report to Congress, Washington DC

Van Vliet OPR, Faaji APC, Turkenburg WC (2009) Fischer-Tropsch diesel production in a well-to-wheel perspective: a carbon, energy flow and cost analysis. Energy Convers Manag 50:855-876

Van Vuuren DP et al (2011) The representative concentration pathways: an overview. Clim Chang 109:5-31

Vassolo S, Döll P (2005) Global-scale gridded estimates of thermoelectric power and manufacturing water use. Water Resour Res 41, W04010

Water Science and Technology Board (WSTB) (2008) Desalination: a national perspective. The National Academy Press, Washington DC

Yang X, Dzieglielewski B (2007) Water use by thermoelectric power plants in the United States. J Am Water Res Assoc 43(1):160-169

Yang CJ, Jackson RB (2012) China's growing methanol economy and its implications on energy and environment. Energ Policy 41:878-884

Younos T, Hill R, Poole H (2009) Water dependency of energy production and power generation systems. VWRRC Special Report No. SR46-2009

Zhai H, Rubin ES, Versteeg PL (2011) Water use at pulverized coal power plants with postcombustion carbon capture and storage. Environ Sci Technol 45:2479-2485 